\title{
Could Ryanair control use of its flight data by PR Aviation without database right?
}

\author{
Gemma Woodhead \\ Journal of Direct, Data and Digital Marketing Practice (2015) 16, \\ 234-235. doi:10.1057/dddmp.2015.15
}

Who: Ryanair Limited (Ryanair) v PR Aviation BV (PR Aviation)

Where: The Court of Justice of the European Union

When: 15 January 2015

Law stated as at: 3 February 2015

What happened

The Directive

Screen-scraping prohibited
The Court of Justice of the European Union (CJEU) recently issued its decision on the interpretation of the Database Directive (96/9/EC) (the Directive) ruling that: (a) the Directive only applies to databases that qualify for copyright and/or sui generis right protection under the Directive and (b) authors of databases that do not qualify for protection under the Directive are free to contractually limit the use of their databases, subject to applicable national law.

\section{Background}

The Directive provides copyright and/or sui generis right protection to qualifying databases. The Directive also establishes mandatory rights for 'lawful users' of databases and provides that any contractual provisions that are contrary to these mandatory rights shall be null and void.

\section{Ryanair v PR Aviation}

PR Aviation is a Dutch company that operated a price comparison website that allowed its customers to compare the cost of and book flights. It used screen-scraping software to extract flight data from other companies' websites, including Ryanair's, and used this data on its own website. However, Ryanair's website terms of use expressly prohibited screen scraping and stated, inter alia, that

Ryanair.com is the only website authorised to sell Ryanair flights. Ryanair does not authorise other websites to sell its flights, whether on their own or as part of a package. You are not permitted to use this website other than for ... private, non-commercial purposes ... The use of automated systems or software to extract data from this website or www.bookryanair.com for commercial purposes, ("screen scraping") is prohibited unless the third party has directly concluded a written licence agreement with Ryanair in which permits it access to Ryanair's 
price, flight and timetable information for the sole purpose of price comparison.

No database rights infringed

\section{Contractual limitations not precluded}

\section{Why this matters}

Ryanair claimed that PR Aviation's actions amounted to infringement of its database rights under the Directive and breach of its website contractual terms of use. Ryanair sued PR Aviation in the Dutch courts.

The Netherlands Supreme Court ruled that the flight data on Ryanair's website did not qualify for copyright or sui generis right protection under the Directive and accordingly dismissed Ryanair's claim for infringement of its database rights. However, it decided to stay the proceedings in relation to Ryanair's claim for breach of contract and requested a preliminary ruling from the CJEU on the following questions:

(a) Does the Directive apply to databases that do not qualify for copyright and/or sui generis right protection under it; and

(b) If the Directive does not apply to such databases, can third parties' use of such databases be contractually limited?

\section{The CJEU's decision}

The CJEU held that it was 'clear from the purpose and structure' of the Directive that it does not apply to databases that are not protected by either copyright or the sui generis right under it. Accordingly, the Directive does not 'preclude the author of such a database from laying down contractual limitations on its use by third parties, without prejudice to the applicable national law'.

This case will be of particular interest to website owners and users of screen-scraping technology. Website owners may wish to review their website terms of use to see whether it is possible to add additional contractual restrictions on third parties' use of their websites.

Conversely, users of screen-scraping technology should be mindful that we may now see an increase in the number of website owners adding contractual restrictions to their website terms of use and bringing breach of contract claims, and they should keep this in mind when reviewing their operating methods and strategies.

Gemma Woodhead, trainee solicitor, Osborne Clarke, London 